OPEN ACCESS

Edited by:

Teresa Giani,

University of Florence, Italy

Reviewed by:

Sezgin Sahin,

Istanbul University-Cerrahpasa, Turkey

Nuray Aktay Ayaz,

Istanbul University, Turkey

${ }^{*}$ Correspondence:

Maryam Piram

maryam.piram.med@ssss.gouv.qc.ca

Specialty section:

This article was submitted to

Pediatric Rheumatology,

a section of the journal

Frontiers in Pediatrics

Received: 27 February 2021

Accepted: 26 April 2021

Published: 25 May 2021

Citation:

Piram M (2021) Epidemiology of Kawasaki Disease in Europe. Front. Pediatr. 9:673554. doi: 10.3389/fped.2021.673554

\section{Epidemiology of Kawasaki Disease in Europe}

\author{
Maryam Piram ${ }^{1,2 *}$ \\ ${ }^{1}$ Department of Pediatrics, Research Centre of the Sainte Justine University Hospital, Sainte Justine University Hospital, \\ University of Montreal, Montreal, QC, Canada, ${ }^{2}$ Centre for Epidemiology and Population Health (CESP), University \\ Paris-Saclay, Le Kremlin Bicêtre, France
}

Aim of the review: To review major epidemiological aspects of Kawasaki disease (KD) in Europe, describing demographic characteristics, revising its incidence along with time trends and geographic variations, and describing migration studies to provide clues about its etiology.

Recent findings: The annual incidence of KD in Europe is about 10-15 per 100,000 children under 5 years old and seems to be relatively stable over time and space. Demographic characteristics are in line with those in other countries of the world, with a higher incidence in children from Asia and possibly North African origin. All studies performed across Europe found a coherent seasonal distribution of KD onset peaking from winter to early spring. This seasonal distribution was consistent over the years and suggests a climate-related environmental trigger. The occurrence of peaks during pandemics, microbiological findings and a possible link with southerly winds support the hypothesis of an airborne infectious agent. Neither other airborne agents such as pollutants or pollens nor urbanization and industrialization seem to have major effect on the etiology.

Conclusion: Discrepancies in KD incidence rates across studies were due more to methodological differences, variation in definitions and awareness of the disease than a real increase in incidence. Genetic predisposition is undeniable in KD, but environmental factors seem to play a pivotal role. Several lines of evidence support a non-exclusive airborne infectious agent with a protective immune response by the host as a key factor in inducing the inflammatory cascade responsible for symptoms and complications.

Keywords: Kawasaki disease, vasculitis, epidemiology, incidence, children, Europe, coronary arterial lesions

\section{INTRODUCTION}

Kawasaki disease (KD) is the main systemic vasculitis of children under 5 years old, affecting predominantly medium-size arteries, particularly coronary arteries. This acute disease, described in 1967 by Tomisaku Kawasaki, is the leading cause of acquired heart disease in childhood in developed countries (1). The disease is described in all continents but with variable frequency. The highest annual incidence is in Asian countries, and the latest published rate (per 100,000 children 
under 5 years old) seems to progressively decrease from 359 in Japan, 197 in South Korea, and 95 in Shanghai to 75 in Taiwan (2-5). In non-Asian countries, the annual incidence is about 1020 per 100,000 children under 5 years old, as described in North America, Europe, Chile or Australia $(6,7)$. In Hawaii, the higher incidence rate of 32 per 100,000 compared to the rest of the United States is due to the large number of children with an Asian origin (8). Little is known about the impact of KD in Africa, South America, and the Near and Middle East.

Despite extensive research, the exact cause of $\mathrm{KD}$ remains unknown. Important clues can be obtained by epidemiological investigations searching for etiologic factors. Disparities in incidence between countries coupled with migration studies showing a higher incidence for children with an Asian origin than Caucasian children support a genetic predisposition to the disease $(8,9)$. Moreover, genome-wide association studies have described polymorphisms associated with the occurrence of $\mathrm{KD}$ or complications $(10,11)$. However, genetics does not explain all of the epidemiological characteristics of the disease. Family forms are rare (2\% in siblings, $1 \%$ in parents) (2). Many countries have reported an increased incidence of KD over the last decades (2$5,12)$. Whether this increase is real or due to increased physician awareness is unclear. In South Korea, Shanghai and Taiwan, incidence rates seem to have stabilized in the last years (3-5). In Japan, where there is a long-standing widespread physician awareness of the disease, the increased incidence might be due to a true increase in case numbers. However, nationwide $\mathrm{KD}$ surveys to monitor KD every 2 years since 1970 throughout Japan showed an increased number of patients with incomplete KD without coronary artery abnormalities in the last 4 decades (2). Therefore, the increased number of patients with incomplete KD without such abnormalities could be due to better recognition of the incomplete form, a real increase of incidence or even an over-diagnosis.

Three epidemic peaks in Japan and the seasonal variation in $\mathrm{KD}$ support the hypothesis of an environmental factor as a trigger for $\mathrm{KD}$. However, seasonal variation differs among countries. Some countries reported peaks of incidence in winter (Japan, Canada) or in spring (Taiwan) and others in summer (Korea) or autumn (India, Costa Rica) or no seasonality (Hawaii) $(8,13)$. Results were in agreement for seasonality in the northern hemisphere, with highest number of cases in January through March, which suggests an infectious agent operating during winter months (14). Results for a link with rainfall were discordant (13). Analyses have correlated the incidence of KD cases in Japan, Hawaii, and San Diego with tropospheric wind patterns originating from northeastern China, which suggests that a wind-borne agent, possibly a fungal toxin from agricultural sources, could trigger the illness (15). In addition, intracytoplasmic inclusion bodies found in ciliated bronchial epithelium in three dead patients suggested a viral air-borne agent (16). However, the role of a defective intestinal barrier function in the development of $\mathrm{KD}$ is under investigation. Increased intestinal permeability with elevated serum immunoglobulin A (IgA) level and changes in intestinal microbiota composition have been described in patients with KD (17). Age of disease onset, self-limited course of this acute disease, and low rate of recurrence suggest an environmental factor, with the host inducing a protective immune response. Bacterial, fungal and viral agents have been incriminated, but none is constantly present or universal, which suggests that nonspecific agents trigger the inflammatory cascade, as observed in auto-inflammatory diseases. Other environmental agents such as toxins, food, and living standards may have modulatory effects (11).

This review aims to describe the major epidemiological aspects of KD in Europe, describing demographic characteristics, revising its incidence along with time trends and geographic variations, and describing migration studies in comparison with other geographic areas to provide clues about its etiology.

\section{INCIDENCE RATES}

Figure 1 illustrates the incidence rates of $\mathrm{KD}$ in European countries. Most of the studies were performed in northern and western European countries, and little is known about the epidemiology of $\mathrm{KD}$ in eastern European countries. The range of incidence rate is broad, with a minimum of 1.6 per 100,000 children under 5 years old in the Czech Republic and a maximum of 17.6 in Italy $(18,19)$. However, the period of the studies and methodological differences could explain these differences. An increased awareness of the disease in the last 20 years combined with a better definition of cases after publication in 2004 of The American Heart Association (AHA) classification criteria for $\mathrm{KD}$ have progressively improved the diagnosis of KD (20).

The incidence of 1.6 per 100,000 children under 5 years old in the Czech Republic comes from a study performed between 1997 and 1999, when many physicians were not aware of KD (18). Moreover, the study was prospective, with a monthly mailed questionnaire sent to heads of pediatric departments. Such voluntary reporting by busy physicians can under-record cases. The United Kingdom has the largest number of studies on the incidence of KD: annual estimates ranged from 3.4 to 15.2 per 100,000 children under 5 years old. In 1990, the incidence in the United Kingdom and Ireland was 3.4 per 100,000 children, but the period and study design were similar to the study performed in the Czech Republic and probably underestimated the true incidence (21). In 1996, using a more accurate methodology with multiple sources of case identification, Gardner-Medwin et al. found an annual incidence of 5.5 per 100,000 children in the West Midlands (England) (22). A capture-recapture analysis estimated that case finding might have missed $40 \%$ of cases. The same year in Ireland, Lynch et al. described an average annual KD hospitalization rate of 15.2 per 100,000 children (23). Because a child could be hospitalized in several hospitals or several times during the same episode, this rate was an overestimation of the true incidence. In 1998, before publication of the AHA criteria and increased awareness of KD by physicians, Harnden et al. found an incidence of 8.4 per 100,000 children by using administrative data (24). Recently, Hall et al. found an incidence of 9.1 per 100,000 children by using The Health Improvement Network database of electronic primary healthcare records from practices throughout the United Kingdom. This database has 


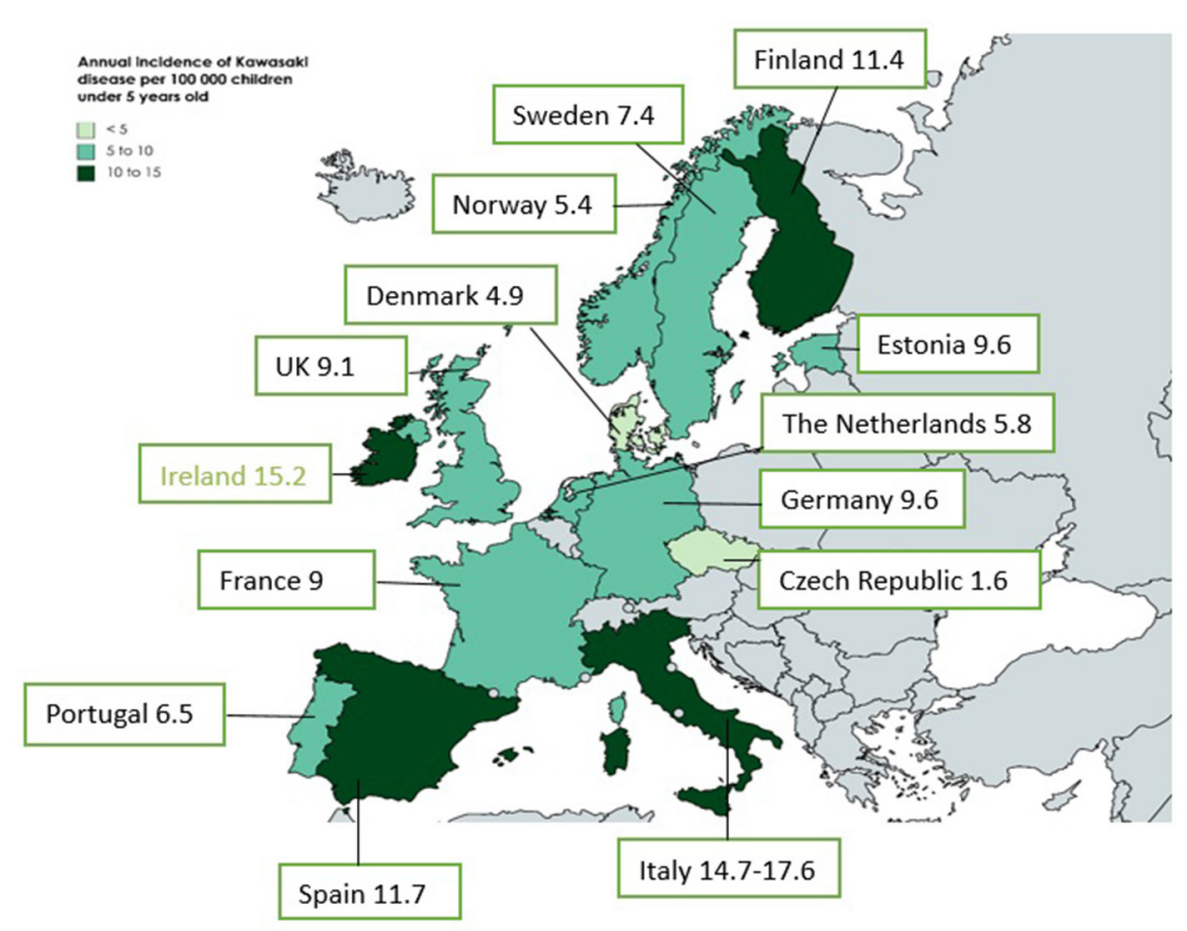

The number in green represents the hospitalization rate in Ireland.

FIGURE 1 | Annual incidence rates of Kawasaki disease in European countries. The number in green represents the hospitalization rate in Ireland.

been shown to be generalizable to the UK population although with slightly fewer people aged $<20$ years as compared with the general UK population (25). Finally, from 2013 to 2015, Tulloh et al. found an annual incidence of 4.6 per 100,000 children with the same methodology used in 1990 and obtained a probable underestimation of the true incidence (26). The slight increase in incidence as compared with 1990 is probably due to increased awareness in the last years and because the authors contacted pediatric cardiologists in addition to pediatricians. These observations underline the importance of the methodology in interpreting results. European studies based on hospital discharge data published in the last 10 years showed annual incidence rates of 9.1-14.7 per 100000 children under 5 years old $(19,25,27,28)$, whereas those based on prospective surveillance found lower rates $(26,29)$ (Table 1). A prospective surveillance design in Germany with cross validation with hospital records from two states found that the hospital-based German Pediatric Surveillance Unit (ESPED) missed $37-44 \%$ of cases. For all these reasons, the incidence of $\mathrm{KD}$ in Europe is probably more 10-15 per 100,000 children under 5 years old.

\section{ETHNICITY AND MIGRATION STUDIES}

Similar to US studies, migration studies performed in the United Kingdom and Spain showed a higher incidence for children with an Asian origin than white peers (22, 24, 31). In
England, a significant association was found between Chinese ethnicity and incidence of KD, peaking at 13.6 instead of 6.6 in areas with more than $1 \%$ of the population of Chinese ethnicity as compared with areas with low $(<0.18)$ population of Chinese ethnicity (24). A weaker association was found between KD incidence in areas of high proportion of black ethnicity (24). In West Midlands, the incidence was 3-fold higher for Asian than white children. However, no children were Chinese, Japanese, or from other countries in the east of the Indian subcontinent but rather were of Indian, Pakistani, or Bangladeshi origin. In Spain, KD was more common in Asian and North African children (31).

\section{TIME TRENDS}

All studies performed across Europe found a coherent seasonal distribution of $\mathrm{KD}$ onset peaking from winter to early spring $(24,26,29,30,32-34)$. This seasonal distribution was consistent over the years $(24,26,32)$ and suggests a climate-related environmental trigger.

The incidence of $\mathrm{KD}$ seemed to remain relatively stable over time in Europe. In Denmark, the incidence progressively increased from 1980 to 1999 owing to increased awareness by physicians, with better diagnosis and an increased tendency for hospitalization, but the incidence has stabilized since 1999 (32). From 2000 to 2011, KD cases ranged from 30 to 50 per year in Portugal, with a mean of 39 cases per year (35). The 
TABLE 1 | Reported annual incidence rate (per 100,000 children under 5 years old) in the last 10 years in European countries.

\begin{tabular}{|c|c|c|c|c|c|}
\hline References & Country & $\begin{array}{l}\text { Study } \\
\text { period }\end{array}$ & Source of case identification & $\begin{array}{l}\text { No. of } \\
\text { cases }\end{array}$ & $\begin{array}{l}\text { Annual } \\
\text { incidence rate }\end{array}$ \\
\hline Cimaz et al. (19) & Italy & 2008-2013 & National hospital discharge record database & 2,901 & 14.7 \\
\hline $\begin{array}{l}\text { Riancho-Zarrabeitia } \\
\text { et al. (27) }\end{array}$ & Spain & $2005-2015$ & $\begin{array}{l}\text { Hospital morbidity survey of the Spanish National Institute } \\
\text { of Statistics (INE) database }\end{array}$ & 3,737 & 11.7 \\
\hline Piia Jogi et al. (28) & Estonia & 2008-2019 & Hospital discharge records & 85 & 9.6 \\
\hline Hall et al. (25) & United Kingdom & $2008-2012$ & The Health Improvement Network (THIN) database & 109 & 9.1 \\
\hline Tulloh et al. (26) & United Kingdom+ Ireland & 2013-2015 & Prospective surveillance & 553 & 4.6 \\
\hline Tacke et al. (29) & The Netherlands & 2008-2012 & Prospective surveillance & 341 & 5.8 \\
\hline Jakob et al. (30) & Germany & 2011-2012 & $\begin{array}{l}\text { Prospective national surveillance (ESPED) }+ \\
\text { cross-validation with hospital record data in } 2 \text { federal states }\end{array}$ & 272 & $7.2-9.6$ \\
\hline
\end{tabular}

annual incidence was relatively stable from 2008 to 2012 in The Netherlands, from 2008 to 2013 in Italy and from 2005 to 2015 in Spain $(19,27,29)$. A study performed from 1981 to 2013 in the University hospital of Lausanne in Switzerland described an increase in number of KD cases since 1981. According to the authors, this increase resulted from better diagnosis of KD due to a better recognition of incomplete forms. Besides the increased awareness of the disease with time, the authors mentioned that the recent increase could be due to an improvement in imaging modalities with better diagnosis of cardiac complications. They also underlined that in more than $50 \%$ of patients, z-score calculations changed the degree of coronary artery involvement from the initial echocardiographic report, which had underestimated the coronary artery lesions in many cases (34). Indeed, using absolute dimension of coronary arteries could underestimate prevalence of anomalies as size of coronary arteries vary with age and body surface (36). Z-scores normalize coronary artery luminal dimension for body surface area and allow comparison across time and populations (1). However, several formulas for $\mathrm{z}$-score calculation have been described yielding discrepant $\mathrm{z}$-scores, which might affect diagnosis and clinical decisions $(1,36)$. Therefore, changes in incidence in Europe seem to be related more to increased awareness by physicians, improved imaging modalities, and modification in classification criteria (AHA and z-score calculation) than to a real increase in incidence.

\section{DEMOGRAPHIC CHARACTERISTICS}

Although KD can occur in young adults and children of all ages, the disease has a pronounced predilection for children 1-5 years old (37-39). In Italy, the annual incidence in children under 15 years old was 5.7 per 100,000 but peaked at 14.7 in children under 5 years old (19). In a Spanish series of 625 children under 16 years old with a diagnosis of $\mathrm{KD}, 79 \%$ of cases were younger than $5,16.5 \%$ younger than 1 and $6.7 \%$ younger than 6 months (40). The reported mean age of onset varies from 1.9 to 2.8 years, but the youngest patients could be as young as 1 month old $(21,26,29,30,32-35,40-43)$. Most studies, except one with very few patients in Austria, found a male predominance, with male-to-female ratios of 1.3-1.8 (19, 21, 24, 26, 29, 30, 33-35, 40$42,44)$. In recent years, $58-80 \%$ of $\mathrm{KD}$ cases were complete as compared with $80-87 \%$ in the 1990 's $(21,30,42,43,45)$. The mean delay to treatment with intravenous Ig was 5.3-10 days $(26,29,34,40,42)$, mostly about 7 days $(21,46,47)$. Overall, $11 \%$ to $23 \%$ of children showed resistance to the first intravenous Ig infusion $(29,34,40,42,46,47)$. Frequencies of coronary artery lesions ranged from 2 to $65 \%(19,21,26,34,35,40,42,46-48)$. This discrepancy is due to variations in definition and assessment of coronary artery involvement, time of evaluation and study design. The disease was recurrent in $<2.5 \%$ of cases $(34,35$, $40,43)$ and mortality $<0.5 \%$ in recent series $(19,26,29,34,35$, $40,42,44,47)$. Familial cases are rare, reported in $<1 \%$ of cases in first- and second-degree relatives (40). Appendix 1 reports the main clinical characteristics of children with $\mathrm{KD}$ reported in descriptive European series of more than 150 affected children.

In adulthood, KD mostly affects young adults, with a mean age at diagnosis of 31 years (range 18-68) and a slight preponderance of males (male/female ratio 1.2) (38). The disease is rare and often misdiagnosed, with a median time to diagnosis of 13 days, cardiogenic shock in $5 \%$ of cases and a high rate of coronary artery aneurysms (19\%) (38).

\section{GEOGRAPHIC VARIATIONS}

Seasonal variations are coherent across Europe, but geographic variations seem discordant. In Germany, KD cases were widely distributed, with no correlation among incidence rates by state and state population density per square kilometer or land under farming (30). In the United Kingdom, more cases occurred in rural than urban areas (26). Conversely, in Portugal and in The Netherlands, the incidence of $\mathrm{KD}$ was higher in regions with a high population density and less agriculture-based economies $(29,35)$. In Catalonia, Spain, most of the cases were concentrated in the most densely populated areas around Barcelona, but a significant difference was observed for the $11.5 \%$ of patients living in rural areas vs. the expected $5 \%$ for the Catalan population according to the national census. Therefore, the authors concluded that $\mathrm{KD}$ was more prevalent in rural than urban areas of Catalonia (31). The incidence of $\mathrm{KD}$ was not related to population density in Italian regions, and the authors wondered if the higher incidence in some regions might reflect better reporting (19). The same discrepancies found in Asia $(15,49,50)$ suggest that urbanization and industrialization are not major etiological factors in the occurrence of KD. 


\section{ENVIRONMENTAL RISK FACTORS}

An epidemiological study performed in two regions in Italy (Emilia and Romagna) found a negative correlation between temperature and number of $\mathrm{KD}$ cases but no correlation with precipitation or quality of air (33). Reduced onset during spring and summer seems to exclude a relation with pollen or fertilizers used in agriculture (33). The occurrence of two epidemic peaks in 2005 and 2013 in Romagna and a possible link with southerly winds and milder temperature in Emilia support the implication of an airborne infectious agent operating during winter months (33). Only $16 \%$ of Spanish patients had positive microbiological findings, but the causative agent was a respiratory virus in $35 \%$ of cases and pharyngeal Streptococcus group A in $29 \%$ (40). A tertiary pediatric center in Paris observed two peaks of hospital admission for KD between 2006 and 2020. The first peak in 2009 was concomitant with the H1N1 pandemic and the second in 2020 with the COVID-19 pandemic (51). These reports support the role of a non-exclusive upper respiratory-tract infection triggering $\mathrm{KD}$. The association of social deprivation with increased incidence of KD in the United Kingdom could also support the causal role of infection but might also include other environmental determinants (24). To date, there is low evidence to incriminate exposure to other airborne agents such as pollutants or pollens (33).

\section{CONCLUSION}

The annual incidence of KD in northern and western European countries is about $10-15$ per 100,000 children under 5 years old and seems to be relatively stable over time and space. From the

\section{REFERENCES}

1. McCrindle BW, Rowley AH, Newburger JW, Burns JC, Bolger AF, Gewitz $M$, et al. Diagnosis, treatment, and long-term management of Kawasaki disease: a scientific statement for health professionals from the American heart association. Circulation. (2017) 135:e927-99. doi: 10.1161/CIR.0000000000000484

2. Ae R, Makino N, Kosami K, Kuwabara M, Matsubara Y, Nakamura Y. Epidemiology, treatments, and cardiac complications in patients with Kawasaki Disease: the nationwide survey in Japan, 2017-2018. J Pediatr. (2020) 225:23-9.e2. doi: 10.1016/j.jpeds.2020.05.034

3. Kim GB, Eun LY, Han JW, Kim SH, Yoon KL, Han MY, et al. Epidemiology of Kawasaki disease in South Korea: a nationwide survey 2015-2017. Pediatr Infect Dis J. (2020) 39:1012-6. doi: 10.1097/INF.0000000000002793

4. Xie LP, Yan WL, Huang M, Huang MR, Chen S, Huang GY, et al. Epidemiologic features of Kawasaki disease in Shanghai from 2013 through 2017. J Epidemiol. (2020) 30:429-35. doi: 10.2188/jea.JE20190065

5. Huang YH, Lin KM, Ho SC, Yan JH, Lo MH, Kuo HC. Increased incidence of Kawasaki disease in Taiwan in recent years: a 15 years nationwide populationbased cohort study. Front Pediatr. (2019) 7:121. doi: 10.3389/fped.2019.00121

6. Hearn J, McCrindle BW, Mueller B, O’Shea S, Bernknopf B, Labelle $\mathrm{M}$, et al. Spatiotemporal clustering of cases of Kawasaki disease and associated coronary artery aneurysms in Canada. Sci Rep. (2018) 8:17682. doi: 10.1038/s41598-018-35848-9

7. Kim GB. Reality of Kawasaki disease epidemiology. Korean J Pediatr. (2019) 62:292-6. doi: 10.3345/kjp.2019.00157 limited data available, the incidence seems to be similar in Eastern Europe. Demographic characteristics of $\mathrm{KD}$ in Europe are in line with those in other countries, with a higher incidence in children with Asian and possibly North African origins. Genetic predisposition is undeniable in this disease, but environmental factors appear to play a pivotal role. Several lines of evidence support that KD may have an infectious origin. Age of onset, selflimited course of the disease, coherent seasonality across Europe with more cases during winter and early spring, the occurrence of epidemic peaks during the H1N1 and COVID-19 pandemics, a possible link with southerly winds and elevated serum IgA level point to an airborne infectious agent operating during the winter months, with the host inducing a protective immune response. Overlapping features of $\mathrm{KD}$ with multisystem inflammatory disease in children described during the COVID-19 pandemic (52) reinforces the hypothesis of an airborne infectious trigger during KD. Studies of this newly described entity will help in understanding the pathogenic mechanisms involved in these two inflammatory diseases and possibly provide clues about host- and pathogen-dependent factors involved in the pathogenesis of KD.

\section{AUTHOR CONTRIBUTIONS}

MP performed the review, drafted the manuscript, and agrees to be accountable for the content of the work.

\section{SUPPLEMENTARY MATERIAL}

The Supplementary Material for this article can be found online at: https://www.frontiersin.org/articles/10.3389/fped. 2021.673554/full\#supplementary-material

8. Dawson TJ, Vuong CT, Ma SCY, Russell CR, Melish ME, Bratincsak A. Mapping the trends of Kawasaki disease in Hawai'i from 1996 to 2018. Hawaii J Health Soc Welf. (2020) 79(Suppl. 1):104-11.

9. Holman RC, Christensen KY, Belay ED, Steiner CA, Effler PV, Miyamura J, et al. Racial/ethnic differences in the incidence of Kawasaki syndrome among children in Hawaii. Hawaii Med J. (2010) 69:194-7.

10. Elakabawi K, Lin J, Jiao F, Guo N, Yuan Z. Kawasaki disease: global burden and genetic background. Cardiol Res. (2020) 11:9-14. doi: 10.14740/cr993

11. Tirelli F, Marrani E, Giani T, Cimaz R. One year in review: Kawasaki disease. Curr Opin Rheumatol. (2020) 32:15-20. doi: 10.1097/BOR.0000000000000671

12. Saundankar J, Yim D, Itotoh B, Payne R, Maslin K, Jape G, et al. The epidemiology and clinical features of Kawasaki disease in Australia. Pediatrics. (2014) 133:e1009-14. doi: 10.1542/peds.2013-2936

13. Piram M, Kone-Paut I. [Kawasaki disease: what's new in 2012?]. Arch Pediatr (2012) 19:1012-4. doi: 10.1016/j.arcped.2012.07.011

14. Burns JC, Herzog L, Fabri O, Tremoulet AH, Rodo X, Uehara R, et al. Seasonality of Kawasaki disease: a global perspective. PLoS ONE. (2013) 8:e74529. doi: 10.1371/journal.pone.0074529

15. Rodo X, Curcoll R, Robinson M, Ballester J, Burns JC, Cayan DR, et al. Tropospheric winds from northeastern China carry the etiologic agent of Kawasaki disease from its source to Japan. Proc Natl Acad Sci USA. (2014) 111:7952-7. doi: 10.1073/pnas.1400380111

16. Rowley AH, Baker SC, Shulman ST, Rand KH, Tretiakova MS, Perlman EJ, et al. Ultrastructural, immunofluorescence, and RNA evidence support the hypothesis of a "new" virus associated with Kawasaki disease. J Infect Dis. (2011) 203:1021-30. doi: 10.1093/infdis/jiq136 
17. Noval Rivas M, Arditi M. Kawasaki disease: pathophysiology and insights from mouse models. Nat Rev Rheumatol. (2020) 16:391-405. doi: 10.1038/s41584-020-0426-0

18. Dolezalova P, Telekesova P, Nemcova D, Hoza J. Incidence of vasculitis in children in the Czech republic: 2-year prospective epidemiology survey. $J$ Rheumatol. (2004) 31:2295-9.

19. Cimaz R, Fanti E, Mauro A, Voller F, Rusconi F. Epidemiology of Kawasaki disease in Italy: surveillance from national hospitalization records. Eur J Pediatr. (2017) 176:1061-5. doi: 10.1007/s00431-017-2947-3

20. Newburger JW, Takahashi M, Gerber MA, Gewitz MH, Tani LY, Burns JC, et al. Diagnosis, treatment, and long-term management of Kawasaki disease: a statement for health professionals from the Committee on Rheumatic Fever, Endocarditis, and Kawasaki Disease, council on cardiovascular disease in the young, American Heart Association. Pediatrics. (2004) 114:1708-33. doi: 10.1542/peds.2004-2182

21. Dhillon R, Newton L, Rudd PT, Hall SM. Management of Kawasaki disease in the British Isles. Arch Dis Childhood. (1993) 69:631-6. doi: 10.1136/adc.69.6.631

22. Gardner-Medwin JM, Dolezalova P, Cummins C, Southwood TR. Incidence of Henoch-Schonlein purpura, Kawasaki disease, and rare vasculitides in children of different ethnic origins. Lancet. (2002) 360:1197-202. doi: 10.1016/S0140-6736(02)11279-7

23. Lynch M, Holman RC, Mulligan A, Belay ED, Schonberger LB. Kawasaki syndrome hospitalizations in Ireland, 1996 through 2000. Pediatr Infect Dis J. (2003) 22:959-63. doi: 10.1097/01.inf.0000095194.83814.ee

24. Harnden A, Mayon-White R, Perera R, Yeates D, Goldacre M, Burgner D. Kawasaki disease in England: ethnicity, deprivation, and respiratory pathogens. Pediatr Infect Dis J. (2009) 28:21-4. doi: 10.1097/INF.0b013e3181812ca4

25. Hall GC, Tulloh LE, Tulloh RM. Kawasaki disease incidence in children and adolescents: an observational study in primary care. Br J Gen Pract. (2016) 66:e271-6. doi: 10.3399/bjgp16X684325

26. Tulloh RMR, Mayon-White R, Harnden A, Ramanan AV, Tizard EJ, Shingadia D, et al. Kawasaki disease: a prospective population survey in the UK and Ireland from 2013 to 2015. Arch Dis Childhood. (2018) 104:7. doi: 10.1136/archdischild-2018-315087

27. Riancho-Zarrabeitia L, Rasilla DF, Roye D, Fdez-Arroyabe P, Santurtun A. Kawasaki disease in Spanish paediatric population and synoptic weather types: an observational study. Rheumatol Int. (2018) 38:1259-66. doi: 10.1007/s00296-018-4066-5

28. Piia Jogi SP, Anna-Liisa V, Eda T, Mari L. Kawasaki Disease in Estonia Between 2008 and 2019. Paris: EURO-KIDs (2021). p. 53.

29. Tacke CE, Breunis WB, Pereira RR, Breur JM, Kuipers IM, Kuijpers TW. Five years of Kawasaki disease in the Netherlands: a national surveillance study. Pediatr Infect Dis J. (2014) 33:793-7. doi: 10.1097/INF.0000000000000271

30. Jakob A, Whelan J, Kordecki M, Berner R, Stiller B, Arnold R, et al. Kawasaki disease in Germany: a prospective, population-based study adjusted for underreporting. Pediatr Infect Dis J. (2016) 35:129-34. doi: 10.1097/INF.0000000000000953

31. Sanchez-Manubens J, Anton J, Bou R, Iglesias E, Calzada-Hernandez J, Rodo $\mathrm{X}$, et al. [Kawasaki disease is more prevalent in rural areas of Catalonia (Spain)]. An Pediatr. (2017) 87:226-31. doi: 10.1016/j.anpede.2017.02.001

32. Fischer TK, Holman RC, Yorita KL, Belay ED, Melbye M, Koch A. Kawasaki syndrome in Denmark. Pediatr Infect Dis J. (2007) 26:411-5. doi: 10.1097/01.inf.0000259964.47941.00

33. Corinaldesi E, Pavan V, Andreozzi L, Fabi M, Selvini A, Frabboni I, et al. Environmental factors and Kawasaki disease onset in Emilia-Romagna, Italy. Int J Environ Res Public Health. (2020) 17:1529. doi: 10.3390/ijerph17051529

34. de La Harpe M, di Bernardo S, Hofer M, Sekarski N. Thirty years of Kawasaki disease: a single-center study at the university hospital of Lausanne. Front Pediatr. (2019) 7:11. doi: 10.3389/fped.2019.00011

35. Pinto FF, Laranjo S, Mota Carmo M, Brito MJ, Cruz Ferreira R. Twelve years of Kawasaki disease in Portugal: epidemiology in hospitalized children. Pediatric Infect Dis J. (2017) 36:364-8. doi: 10.1097/INF.0000000000001444

36. Kim SH, Kim JY, Kim GB, Yu JJ, Choi JW. Diagnosis of coronary artery abnormalities in patients with Kawasaki disease according to established guidelines and Z score formulas. J Am Soc Echocardiogr. (2021). doi: 10.1016/j.echo.2021.01.002. [Epub ahead of print].
37. Manlhiot C, Yeung RS, Clarizia NA, Chahal N, McCrindle BW. Kawasaki disease at the extremes of the age spectrum. Pediatrics. (2009) 124:e410-5. doi: 10.1542/peds.2009-0099

38. Fraison JB, Seve P, Dauphin C, Mahr A, Gomard-Mennesson E, Varron L, et al. Kawasaki disease in adults: observations in France and literature review. Autoimmun Rev. (2016) 15:242-9. doi: 10.1016/j.autrev.2015.11.010

39. Grasa CD, Fernandez-Cooke E, Sanchez-Manubens J, Anton J, Crespo D, Garcia M, et al. Kawasaki disease in infants 3 months of age and younger: a multicentre Spanish study. Ann Rheum Dis. (2019) 78:289-90. doi: 10.1136/annrheumdis-2018-213891

40. Fernandez-Cooke E, Barrios Tascon A, Sanchez-Manubens J, Anton J, Grasa Lozano CD, Aracil Santos J, et al. Epidemiological and clinical features of Kawasaki disease in Spain over 5 years and risk factors for aneurysm development. 2011-2016: KAWA-RACE study group. PLoS ONE. (2019) 14:e0215665. doi: 10.1371/journal.pone.0215665

41. Salo E. Kawasaki disease in Finland in 1982-1992. Scand J Infect Dis. (1993) 25:497-502. doi: 10.3109/00365549309008532

42. Piram M, Darce Bello M, Tellier S, Di Filippo S, Boralevi F, Madhi F, et al. Defining the risk of first intravenous immunoglobulin unresponsiveness in non-Asian patients with Kawasaki disease. Sci Rep. (2020) 10:3125. doi: 10.1038/s41598-020-59972-7

43. Schiller B, Fasth A, Bjorkhem G, Elinder G. Kawasaki disease in Sweden: incidence and clinical features. Acta Paediatr. (1995) 84:769-74. doi: 10.1111/j.1651-2227.1995.tb13753.x

44. Binder E, Griesmaier E, Giner T, Sailer-Hock M, Brunner J. Kawasaki disease in children and adolescents: clinical data of Kawasaki patients in a western region (Tyrol) of Austria from 2003-2012. Pediatr Rheumatol Online J. (2014) 12:37. doi: 10.1186/1546-0096-12-37

45. Sanchez-Manubens J, Anton J, Bou R, Iglesias E, Calzada-Hernandez J, Kawasaki Disease in Catalonia Working G. Incidence, epidemiology and clinical features of Kawasaki disease in Catalonia, Spain. Clin Exp Rheumatol. (2016) 34(Suppl. 97):S139-44.

46. Maggio MC, Corsello G, Prinzi E, Cimaz R. Kawasaki disease in sicily: clinical description and markers of disease severity. Ital J Pediatr. (2016) 42:92. doi: 10.1186/s13052-016-0306-Z

47. Stasiak A, Smolewska E. Retrospective study of the course, treatment and long-term follow-up of Kawasaki disease: a single-center experience from Poland. Rheumatol Int. (2019) 39:1069-76. doi: 10.1007/s00296-019-04286-9

48. Heuclin T, Dubos F, Hue V, Godart F, Francart C, Vincent P, et al. Increased detection rate of Kawasaki disease using new diagnostic algorithm, including early use of echocardiography. J Pediatrics. (2009) 155:695-9.e1. doi: 10.1016/j.jpeds.2009.04.058

49. Chang WP, Wu SJ, Chang WC, Kuo HC. Population-based study of the association between urbanization and Kawasaki disease in Taiwan. ScientificWorldJournal. (2013) 2013:169365. doi: 10.1155/2013/169365

50. Park YW, Han JW, Hong YM, Ma JS, Cha SH, Kwon TC, et al. Epidemiological features of Kawasaki disease in Korea, 2006-2008. Pediatr Int. (2011) 53:36-9. doi: 10.1111/j.1442-200X.2010.03178.x

51. Ouldali N, Pouletty M, Mariani P, Beyler C, Blachier A, Bonacorsi S, et al. Emergence of Kawasaki disease related to SARS-CoV-2 infection in an epicentre of the French COVID-19 epidemic: a time-series analysis. Lancet Child Adolesc Health. (2020) 4:662-8. doi: 10.1016/S2352-4642(20) 30175-9

52. Cherqaoui B, Kone-Paut I, Yager H, Bourgeois FL, Piram M. Delineating phenotypes of Kawasaki disease and SARS-CoV-2-related inflammatory multisystem syndrome: a French study and literature review. Rheumatology. (2021). doi: 10.1093/rheumatology/keab026. [Epub ahead of print].

Conflict of Interest: The author declares that the research was conducted in the absence of any commercial or financial relationships that could be construed as a potential conflict of interest.

Copyright (c) 2021 Piram. This is an open-access article distributed under the terms of the Creative Commons Attribution License (CC BY). The use, distribution or reproduction in other forums is permitted, provided the original author(s) and the copyright owner(s) are credited and that the original publication in this journal is cited, in accordance with accepted academic practice. No use, distribution or reproduction is permitted which does not comply with these terms. 